\title{
A Probe Into the Teaching Process of Engineering Courses in Colleges and Universities
}

\author{
Ruochen Zhao ${ }^{1, *}$, Yuechun $\mathrm{Ma}^{1}$, Xiaolei Wang ${ }^{1}$, Yanan Sun ${ }^{1}$, Mingyuan Wang ${ }^{1}$ \\ ${ }^{1}$ Engineering Management Department, Inner Mongolia Honder College of Arts and Sciences, Hohhot, Inner \\ Mongolia, 010070, China \\ *Corresponding author. Email: 20201800230@imut.edu.cn
}

\begin{abstract}
The teaching process is a systematic project of the integration of teaching and learning, in which the relationship between the components has a direct impact on the teaching effect. The purpose of this paper is to explore the main problems existing in the teaching of engineering courses in colleges and universities, so as to provide solutions for improving teaching quality. The main contents include effective introduction of teaching content, optimization of teaching content framework, improvement of teaching language skills and timely summary of teaching content.
\end{abstract}

Keywords: Engineering Courses, Teaching Process, Teaching Skills, Content Framework

\section{INTRODUCTION}

In the teaching process of engineering courses in colleges and universities, students' inquiry, practice and innovation should be paid attention to, and teachers' inspiration, guidance and inspiration should be emphasized. In addition, attention should be paid to the process of learning knowledge and the cultivation of students' thinking ability ${ }^{[1-5]}$. The basic links are as follows: guidance-inquiry-intensive lecture-refinementexpansion, As shown in Figure 1.

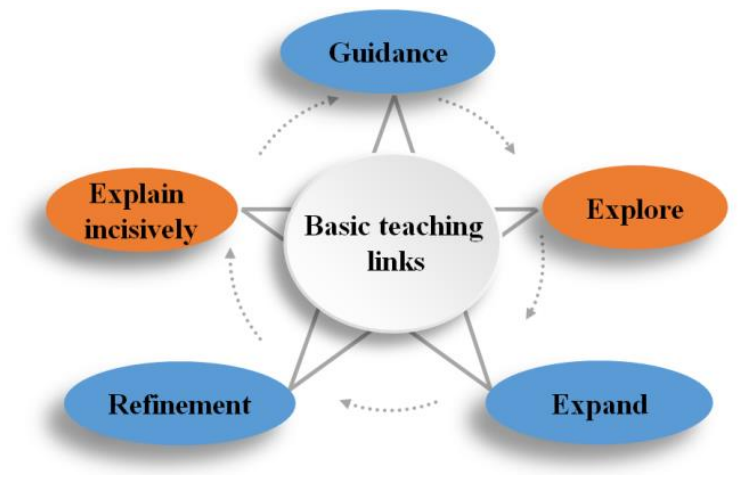

Figure 1 basic teaching links

Specifically, in the process of teaching [6-8]. we should pay attention to the introduction of the overall framework of the discipline to help students learn and transfer; guide students to explore the scientific theory and practical knowledge of the subject; select key contents and elaborate on key contents; arrange homework after class to improve the ability of analysis and calculation; and finally, carry out practice to improve perceptual knowledge ${ }^{[9-11]}$.

\section{EFFECTIVELY INTRODUCE TEACHING CONTENT}

Many things in nature have skillfully mastered and applied the principles of science carelessly or inadvertently. Eagles hit the sky, fish flying shallow bottom, animals use instinct to show the brilliant knowledge of fluid mechanics, human beings have expanded the time and space of life. If we can start the teaching process with phenomena in life, it will inevitably arouse students' interest and eliminate students' emotion that it is difficult for students to learn this course before they learn it. For example, why do umbrellas turn up on rainy days, passengers can't get too close to the train passage on the platform, golf balls are made into rough surfaces with concave spots, what's the trick of pouring beer, and so on. All these can be used as teaching cases. It is out of curiosity and love of life, from a keen sense of touch to calm reflection, the achievement of a great scientific and technological civilization, scientific research comes from the observation and curiosity of life, and education should be the same.

In addition, the life and production examples within reach should be fully utilized, from phenomenon 
induction to theoretical advancement, which is not only conducive to the logical derivation in the teaching process, but also conforms to the students' learning thinking from simple to complex. A good introduction or introduction is the key point to grasp the mind of the students. Only when the students' attention is brought into the preset atmosphere of the teachers, can the teaching be better carried out. As far as this course is concerned, we have received good feedback from the students.

\section{OPTIMIZE THE FRAMEWORK OF TEACHING CONTENT}

Generally speaking, the content of basic courses for engineering majors can be divided into two parts: one is the theoretical system composed of basic concepts and basic theories, and the other is the system of engineering practice and application. The former is highly abstract and emphasizes theoretical derivation. If the primary and secondary cannot be clearly distinguished and the core content cannot be identified, the teacher can only start teaching blindly, causing students to be confused about the logical framework, and then feel a sense of fear. Therefore, the teaching content should be properly summarized and classified, and the three-dimensional knowledge structure should be constructed and constantly condensed and improved in the teaching process. The second part is the practical application of the theory, involving specific concepts, which is the test and second profound grasp of the application of the theoretical system. In view of the students' professional characteristics, typical engineering sample questions with professional characteristics should be selected as the explanation content, and the teaching content should be guided by examples. This enables students to have a thorough understanding of the teaching content, clear thinking, and solve practical engineering problems, achieving the effect of theory guiding practice and practice feeding theory, As shown in Figure 2

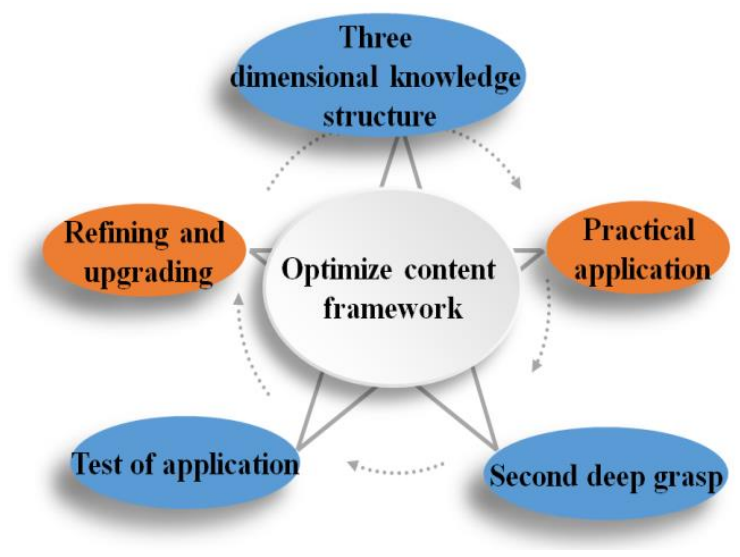

Figure 2 optimized content framework

\section{IMPROVE THE SKILLS OF TEACHING LANGUAGE}

Engineering courses have the characteristics of wide range of basic knowledge, many concepts, abstract content and so on, which explains why it is necessary to turn boring theoretical content and teaching process into vivid narration. In order to firmly attract the attention of students and make the teaching content lively, lively and interesting, language skills are particularly important. It enables the organic combination of teaching and students' language habits, which is beneficial to students' cognition and understanding. This is of great benefit to the promotion of the teaching process, contributing to improving teachers' language vitality, maintaining teachers' language attractiveness, seizing students' classroom attention and improving teaching quality.

The teaching of engineering courses aims to allow students to master knowledge and apply it to work practice. Therefore, the teaching process should not become a teacher's performance class, students should actively participate and become the protagonist of teaching. In the teaching process, arrange students' work, fully mobilize students' learning enthusiasm and subjective initiative, guide students to solve problems autonomously, and summarize the most reasonable answers to give full play to students' subjective initiative. This may be achieved by combining the corresponding arrangements before, during and after class. For example, set the key learning goals of the chapter before class, presuppose the problems to be solved, and guide students to study independently on the comprehensive platform of network teaching, so that students can achieve the purpose of mastering knowledge through preview and reading. In class, it may be possible to arrange a certain amount of class discussion. Through discussion and teachers' on-the-spot carding, we can make knowledge organized and logical, and deepen students' understanding and mastery, which can not only make full and effective use of classroom time, but also consolidate students' knowledge accumulation. Appropriate and appropriate exercises should be arranged after class, and the suitability of after-class assignments is particularly important. But it is worth noting that the homework can not be arranged mechanically, the homework should really play a role of consolidation and training.

In addition, cultivating students' good study habits and training students' analytical ability and self-study ability is also an important guarantee for students to enter the learning atmosphere of the course smoothly. Students are required to summarize the main points of the course, set up study groups, encourage frequent exchanges among students, and introduce learning experiences and learning methods to each other. According to the level of students to designate relevant 
reference books and related journals and magazines, as far as possible to expand the scope of students' knowledge and the frontier of discipline development.

\section{SUMMARIZE THE TEACHING CONTENT IN TIME}

In the process of classroom teaching, the main content and logical relationship of the chapter should be introduced in

The teaching process is a systematic project of teaching and learning, in which the relationship between the components has a direct impact on the teaching effect. "there is a law in teaching, but there is no definite method, the most important thing is to get the method". Teachers need to constantly summarize and sum up in the teaching process, renew teaching ideas, innovate teaching methods, pay attention to every link in the teaching process, and adopt a multi-pronged approach. change teaching into teaching and teach it, and finally realize a developed and innovative model of higher education.review content is arranged on the network teaching platform, and the teachers and students make a summary and discussion at the end of the chapter at the same time.

In addition, a logical framework should be established between the major chapters to help students understand and connect the whole curriculum systematically. Perhaps, it can be summarized in the form of questions on the basis of a specific example. For example, when summarizing the subsections of liquid pressure acting on planes and curved surfaces, an example can be cited, that is, if the flow of a channel is to be intercepted, what factors should be considered in the selection of the gate, and why should these factors be considered. Then, students will naturally apply the knowledge they have learned to think and answer, etc., making the effect of teaching summary more effective.

\section{INTEGRATION OF ELEMENTS OF IDEOLOGICAL AND POLITICAL THEORIES TEACHING IN ALL COURSES}

The core of ideological and political theories teaching in all courses in colleges and universities should be in the process of teaching, actively implement the basic requirements of establishing morality and cultivating people, and imperceptibly carry out ideological guidance. Through active exploration and in-depth excavation of the educational elements contained in the courses, the teachers of various courses form "aggregation", look for the meeting point of their combination with various knowledge points, and organically integrate these elements into the knowledge points taught to form a "mix". In addition, we should realize the ideological guidance in the education and teaching of students, promote the deepening of students' ideological understanding and the gradual promotion of values, form a "combination", and guide students to know the right and wrong before the direction of the road, and then how to act.

In this way, we can maintain a section of canals, plant a good field of responsibility, make all kinds of courses and ideological and political courses go together, unify explicit education and recessive education, form a synergistic effect, and build a pattern of all-round education for the whole staff..

In this way, students are enabled to gain a deeper understanding of China's earthquake-resistant super high-rise buildings, giant water conservancy projects such as the Yangtze River three Gorges Project, and large offshore oil production platforms, as well as advantages and disadvantages, and understand the hardships of several generations of Chinese scientific work. This will inevitably inspire students to study hard, love the motherland, and contribute to the construction of the motherland in the future.

\section{CONCLUSION}

The teaching process is a systematic project of teaching and learning, in which the relationship between the components has a direct impact on the teaching effect. "there is a law in teaching, but there is no definite method, the most important thing is to get the method". Teachers need to constantly summarize and sum up in the teaching process, renew teaching ideas, innovate teaching methods, pay attention to every link in the teaching process, and adopt a multi-pronged approach. change teaching into teaching and teach it, and finally realize a developed and innovative model of higher education.

\section{AUTHORS' CONTRIBUTIONS}

Yuechun Ma and Xiaolei Wang contributed to the conception of the study;Ruochen Zhao contributed significantly to analysis and manuscript preparation;Yanan Sun and Mingyuan Wang helped perform the analysis with constructive discussions.

\section{ACKNOWLEDGMENTS}

The authors would like to thank Inner Mongolia Honder College of Arts and Sciences for helpful discussions on topics related to this work. The authors would like to thank the editor and the reviewers for their useful feedback that improved this paper, and the anonymous reviewers for their helpful remarks.

\section{REFERENCES}

[1] Huang, T.T., Li Y., Yang, Z.G., Yao H.L., Pan H., $\mathrm{Yu}$ X.H. Research on the main changes and 
characteristics of science teaching methods. In: Research on the development of teachers' teaching ability. 2018 pp. 1512-1516.

[2] Kang, L.J. Development Strategies of Uni-versity Education under the Background of Digital T-eaching. In: Shanxi High Quality Development Foru-m in the Digital Era. TY. 2020 pp. 104-110.

[3] Qu, Z.Y. On the Development of Quality Education. In: The 8th High-level Forum on Quality Education of Universities, 2019 Annual Meeting of the Research Branch of Quality Education of China Association for Higher Education. HZ. 2019 pp. 8-12.

[4] Wang, L.N. Study on the Good Interactio-n between Teachers and Students in College Classroom -- A Case Study of A University Education Majo-r. In: Liaoning Higher Education Association 2017 Annual Conference. SY. 2018 pp. 72-86.

[5] Roland M. Schulz. Shifting the Focus of Undergraduate Physics and Engineering Courses Calvin S. Kalman (2017). Successful Science and Engineering Teaching in Colleges and Universities (2nd Ed). Information Age Publishing, Inc., Charlotte, NC. ISBN: 978-1-68123-957-6. 175 pages. US \$49.00 (Paperback)[J]. Science \& Education: Contributions from History, Philosophy and Sociology of Science and Mathematics, 2019,28(9-10).

[6] Qian Cai Exploration of the "New Engineering" Construction Situation and Path--Take Southwest University as an Example[J] International Core Journal of Engineering, 2021, 7(3).

[7] Engineering Analysis; New Engineering Analysis Findings from University of Seville Outlined (A BEM-FEM using layered half-space Green's function in time domain for SSI analyses)[J] Journal of Engineering, 2015.

[8] Cai Yang. Kong, W.W., Lian Y.S., Jin X.X. De -pressive Symptoms among Chinese Informal Employees in the Digital Era. [J] International Jo -urnal of Environmental Research and Public $\mathrm{H}$ -ealth,2021.

[9] Cai Yang Hui;Galili Nir;Gelman Y.;Herzberg M -oshe;Gilron Jack Evaluating the impact of pretr -eatment processes on fouling of reverse osmosi -s membrane by secondary wastewater $[\mathrm{J}]$ Journ -al of Membrane Science,2021.

[10] Liu, L.L.,Deng, Y.J.,Cai Y.,Lu P.F. Ablation of Gsa impairs renal tubule proliferation after injury via CDK2/cyclin E. [J] American Journal o -f Physiology Renal Physiology,2020.
[11] Azam Nikzad, Berisso Kebede, Jaime Pinzon, Jani Bhavikkumar, Rong - Cai Yang. Habibur Rahman Potential of the C Genome of Different Variants of Brassica oleracea for the Improvement of Agronomic and Seed Quality Traits of B. napus Canola [J] Crop Science,2019. 